\title{
Selenium, liver necrosis and depigmentation of incisors in the rat
}

\author{
BY K. ATERMAN* \\ Department of Anatomy, Medical School, Birmingham $\mathbf{1} 5$ \\ (Received I April 1958-Revised 23 September 1958)
}

If rats are fed on a diet containing yeast as the only source of protein, the 'necrogenic yeast diet' of Lindan \& Himsworth (1950), they invariably develop a severe, fatal necrosis of the liver. Himsworth (1950) has pointed out that the course of this disorder is characterized by the fact that the hepatic necrosis sets in without any preliminary warning, after a latency of varying length, during which the experimental animal appears more or less normal. Careful observation, however, shows that most animals develop, at some stage of this latent interval, pronounced depigmentation of the upper and, to a lesser degree, the lower incisors. This dental depigmentation has received a good deal of attention (for literature see, for instance, Moore \& Mitchell, r955), and several substances have been tested for their ability to influence the depigmentation. The course and incidence of liver necrosis can be significantly modified by the administration of such diverse substances as cystine, vitamin $\mathrm{E}$, methylene blue, methylthiouracil and cortisone. A comparative study of the effect of these substances is now being made, and we have found that only tocopherol was able to prevent depigmentation of the rat's teeth. The recent report (Schwarz \& Foltz, 1957) that a small addition of sodium selenite also prevents the onset of liver necrosis suggested a study of the effect of selenium on the colour change in the incisors of the rats fed on the necrogenic diet.

For the experiment here described weanling rats were used, since unpublished work had shown that the course of liver necrosis is the same in weanling as in older animals, except for the much earlier onset of the fatal liver changes in the younger rats. Although the teeth of weanling rats at the beginning of the experiment are white, they become pigmented after a time, despite the ingestion of the deficient diet; but if the animal lives long enough the incisors become depigmented to various extents, until they finally assume a characteristic white colour. This course of events corresponds to the description given by Moore \& Mitchell (1955), who drew attention to the delay in onset of depigmentation of teeth in rats fed on a diet deficient in vitamin $\mathrm{E}$.

\section{EXPERIMENTAL}

Male albino rats, numbering fifteen pairs of litter-mates, of a strain bred in the Department of Anatomy, Birmingham, were used. They were weaned on the 2ist day, the Ist day of the experiment, and were placed in individual cages with raised screen floors. One litter-mate of each pair was given the necrogenic diet of Lindan \&

\footnotetext{
* Present address: Department of Pathology, Dalhousie University, Halifax, Nova Scotia, Canada.
} 
Himsworth (Table I), and its brother the same diet supplemented with 20 p.p.m. sodium selenite. All animals were allowed to die spontaneously or were killed under light ether anaesthesia as soon as it became apparent that death was imminent. The teeth were inspected at weekly intervals.

Table I. Percentage composition of 'necrogenic yeast diet' (Lindan $\Xi$ Himsworth, 1950)

Dried baker's yeast (Distillers Co. Ltd, Edinburgh) $\quad{ }_{18}$

Maize starch

Olive oil

Cod-liver oil

Salt mixture (Glaxo Laboratories Ltd)

73

5

3

Added vitamins (mg/lo g food): thiamine hydrochloride, 20; pyridoxine, 20 ; riboflavin, 25 ; calcium pantothenate, roo.

\section{RESULTS AND DISCUSSION}

The results are presented in Table 2 . All rats fed on the unsupplemented necrogenic diet died of liver necrosis, their survival time varying from 26 to 57 days (mean $35^{\circ} 4$ days). All their litter-mates given the diet supplemented with selenite died, however, significantly later, with survival times ranging from 63 to 162 days (mean I20.5 days). The considerable variation in the survival time of this group was not determined by the initial weight of the animals. The treated rat of pair no. 8 , for

Table 2. Survival time, incidence of liver necrosis and depigmentation of upper incisors of rats fed on the 'necrogenic yeast diet' with and without a supplement of 20 p.p.m. sodium selenite

\begin{tabular}{|c|c|c|c|}
\hline Observation & $\begin{array}{l}\text { Pair } \\
\text { no. }\end{array}$ & $\begin{array}{c}\text { Without } \\
\text { supplement }\end{array}$ & $\begin{array}{l}\text { With } \\
\text { supplement }\end{array}$ \\
\hline \multirow[t]{16}{*}{ Survival time (days) } & $\mathbf{I}$ & 26 & 162 \\
\hline & 2 & 26 & 92 \\
\hline & 3 & 28 & 75 \\
\hline & 4 & 28 & 132 \\
\hline & 5 & 28 & 144 \\
\hline & 6 & 29 & 130 \\
\hline & 7 & 30 & II 7 \\
\hline & 8 & 3 I & 63 \\
\hline & 9 & $3^{I}$ & I 44 \\
\hline & Io & 33 & I 55 \\
\hline & I I & 35 & 102 \\
\hline & 12 & 40 & I 38 \\
\hline & 13 & 55 & 99 \\
\hline & 14 & 55 & I6I \\
\hline & I 5 & 57 & I 34 \\
\hline & Mean & $35^{\circ} 4$ & $120 \cdot 5$ \\
\hline Total no. with liver necrosis & & I5 & $\circ$ \\
\hline $\begin{array}{l}\text { Degree of dental depigmenta- } \\
\text { tion at time of death }\end{array}$ & & Variable & Complete \\
\hline
\end{tabular}

instance, weighed at the beginning of the experiment $28 \mathrm{~g}$ and survived for 63 days, but the treated animal of pair no. 7 , with the same initial weight, lived for 117 days. Conversely, the animal with the longest survival time of 162 days (pair no. I) weighed 
at the outset only $3 \circ \mathrm{g}$, whereas the heavier rat of pair no. 13 with an initial weight of $35 \mathrm{~g}$ lived only for 99 days. Nor could there be found any close correlation between the favourable effect of selenite on the survival time and the rate of growth of the experimental animals. As was to be expected, animals that survived longer tended to be heavier. The rat with the longest survival time of 162 days (pair no. I), for instance, increased its weight from 30 to $105 \mathrm{~g}$ during that period, whereas the treated rat with the shortest survival time of $6_{3}$ days (pair no. 8) had not gained in weight by the time of death. On the other hand, the fact (exemplified by the treated rat of pair no. 8) that a significant prolongation of survival time can take place with no, or hardly any, change in weight must be taken into consideration. The treated rat of pair no. $\mathrm{I}_{5}$, for instance, lived for 134 days, but its weight gain during that period was only $5 \mathrm{~g}$, from 32 to $37 \mathrm{~g}$. The effect of supplements of selenium on the rate of growth was, therefore, by no means uniform. It is noteworthy, however, that no animal of this group died of liver necrosis. Macroscopic examination of the liver at the time of death showed no evidence of present or past liver damage, in the form of either haemorrhage, necrosis, or scarring. The cause of death of these rats is unknown, and suggests the need for further detailed investigation.

Despite the continuous administration of sodium selenite depigmentation of the upper, and sometimes also of the lower, incisors gradually became apparent (Pl. I). In young animals the presence of dental depigmentation is sometimes difficult to assess, but as time progressed it became apparent that the development and the final appearance of this depigmentation differed in no way from that known to occur in rats fed on a diet deficient in tocopherol and prevented by it (Davies \& Moore, I94I). Of interest, for the purpose of the present paper, is the fact that, in all animals given the supplement of selenium, depigmentation of the upper incisors in time became complete, and once established remained so. The appearance of dental depigmentation did not seem related to the time of survival, since of two treated rats with an equal degree of depigmentation one (pair no. 3 ) died after 75 days, whereas the other (pair no. 6) lived for $\mathrm{I} 30$ days. The earliest complete depigmentation was noted after about 43 days in the treated animal of pair no. 10, which survived for another 72 days. From these observations it can, therefore, be concluded that although supplements of selenium and of vitamin $E$ have similarly favourable effects on the cause and the incidence of liver necrosis in rats fed on the necrogenic diet, this parallelism appears not to extend to the metabolic disturbance underlying the depigmentation of the rats' incisors.

\section{SUMMARY}

I. Fifteen pairs of litter-mate male albino rats were fed from weaning on a diet with baker's yeast as the sole source of protein. One animal of each pair was given the diet alone and the other the diet supplemented with 20 p.p.m. sodium selenite.

2. Whereas all the unsupplemented animals developed fatal liver necrosis, the supplement of sodium selenite not only prevented the onset of liver necrosis in their litter-mate controls, but also significantly prolonged their survival time.

3. Despite this favourable effect of selenium on the survival time, and on the 

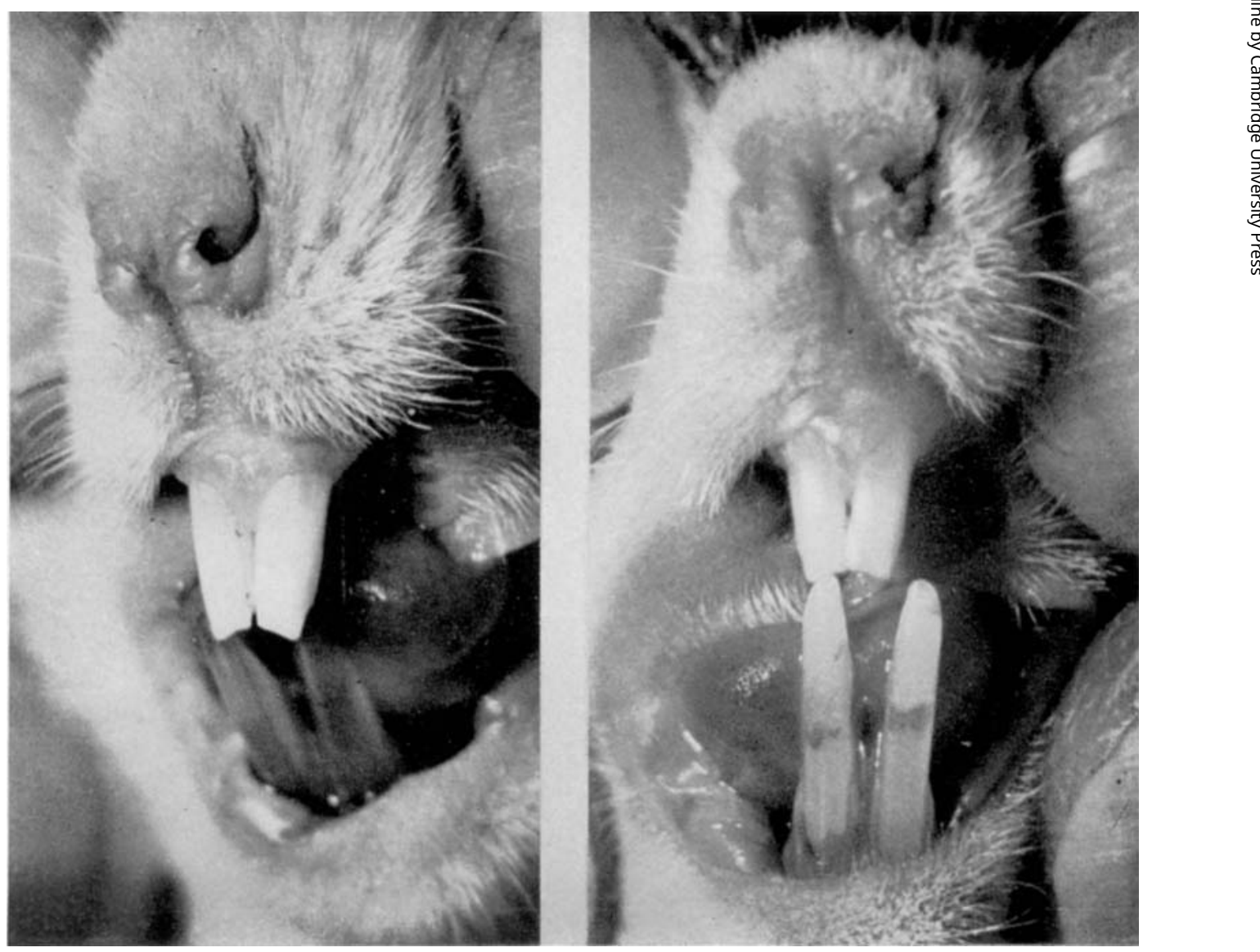

British Fournal of Nutrition, Vol. 13, No. I 
incidence of liver necrosis, it had no apparent effect on the depigmentation of the rats' incisors which takes place if these animals are fed on a diet deficient in tocopherol, and which is prevented only by this vitamin.

4. The parallelism between the effect of selenium and of vitamin E, both of which prevent liver necrosis and prolong the survival time of deficient rats, therefore does not extend to the disturbance causing dental depigmentation.

\title{
REFERENCES
}

Davies, A. W. \& Moore, T. (1941). Nature, Lond., 147, 794.

Himsworth, H. P. (1950). Lectures on the Liver and its Diseases, 2nd ed. Oxford: Blackwell.

Lindan, O. \& Himsworth, H. P. (1950). Brit. F. exp. Path. 31, 65 I.

Moore, T. \& Mitchell, R. L. (1955). Brit. F. Nutr. 9, 174.

Schwarz, K, \& Foltz, C. M. (1957). F. Amer. chem. Soc. 79, 3292.

Depigmentation of upper incisors in two rats fed on the 'necrogenic diet', supplemented with 20 p.p.m. sodium selenite, for 82 days. Whereas the lower incisors of the animal on the left are still normal in colour, they have become almost completely white in the animal on the right.

\section{Determination of the total daily energy expenditure in man by indirect calorimetry: assessment of the accuracy of a modern technique}

\author{
By J. V. G. A. DURNIN AND J. M. BROCKWAY \\ Institute of Physiology, University of Glasgow
}

(Received 8 May 1958-Revised 27 September 1958)

There have been several descriptions recently of experiments to determine, by indirect calorimetry, the total energy expenditure of human beings. With a few exceptions (for example, that of Booyens \& McCance (1957) who used the Douglas bag) these surveys have utilized the Max Planck respirometer (Kofranyi \& Michaelis, 1940; Müller \& Franz, 1952). This instrument was employed for measuring the energy expenditure of the various activities of the subjects, and the duration in time of each separate activity was also recorded. Some examples of such surveys are those of Lehmann, Müller \& Spitzer (1950); Passmore, Thomson \& Warnock (1952); Garry, Passmore, Warnock \& Durnin (1955); Durnin, Blake \& Brockway (1957); Welch, Marcinek, Buskirk \& Iampietro (1957); Brockett, Konishi, Brophy, Marcinek, Michalowicz, Grotheer \& Kashin (r957). The present paper is an attempt to assess the accuracy of such measurements.

There are several possible sources of error in determining the total energy expenditure of a human being living under normal everyday conditions, especially if the survey is of some days' duration and attempts to cover all $24 \mathrm{~h}$ of the day in contrast 